\title{
农业灌溉用水经济价值及其影响因素 基于剩余价值法和陕西关中地区农户调研数据
}

\author{
刘维哲,唐 溧, 王西琴, 王建浩 \\ (中国人民大学农业与农村发展学院,北京 100872)
}

\begin{abstract}
摘要: 灌溉水经济价值是农业用水定价的重要基础。根据陕西关中地区农户调研数据, 采用剩 余价值法计算得到小麦、玉米和苹果灌溉水经济价值均值分别为 0.66 元 $/ \mathrm{m}^{3} 、 0.84$ 元 $/ \mathrm{m}^{3} 、 3.17$ 元 $/ \mathrm{m}^{3}$ 。以该结果作为水价调整上限与现状水价比较, 小麦和玉米的水价上调空间介于 0.24 0.71 元 $/ \mathrm{m}^{3}$, 苹果的水价调整空间介于 2.72 3.04 元 $/ \mathrm{m}^{3}$ 之间。使用分位数模型对影响因素的研 究发现: (1)仅在灌溉水经济价值较低时, 农户和家庭特征以及土地分散程度有显著影响; (2) 在灌溉水经济价值较高时, 增强农户节水意识以及加人用水者协会将能有效提升灌溉用水经 济价值; (3)粮食转为经济作物、进行农业水价综合改革在所有分位点上均呈显著正向影响。 本文可为研究区域农业用水分类定价及改善用水效率提供参考。
\end{abstract}

关键词: 灌溉水经济价值; 影响因素;剩余价值法;分位数模型;关中地区

中国是一个水资源丰富的国家，水资源总量位居世界第四，但同时又是一个人均水 资源短缺的国家，不足世界平均水平的 $1 / 4$ 。从用水结构来看，农业为最主要的用水部 门, 约占总用水量的 $62 \%$ 。而当前中国农业用水效率低下, 灌溉水有效利用系数为 0.5 , $1 \mathrm{~m}^{3}$ 灌溉水粮食产量为 $1.1 \mathrm{~kg}$, 远低于发达国家灌溉水有效利用系数 $0.7 \sim 0.8,1 \mathrm{~m}^{3}$ 灌溉 水粮食产量为 $2.5 \sim 3.0 \mathrm{~kg}$, 这进一步加剧了农业用水紧张状况 ${ }^{[1]}$ 。因此, 如何提高水资源 使用效率已经成为解决当前农业用水短缺状况的迫切需求。而合理的水价调整和农业用 水有效分配是提高区域用水效率的重要途径。对灌溉水经济价值的研究不仅是合理水价 调整的重要基础, 还是农业水资源管理部门在不同区域、作物之间做出有效分配的依 据。水资源经济价值是理性使用者将水资源作为生产要素进行生产所得的单纯由水资源 创造的经济价值 ${ }^{[2]}$ 。农业灌溉用水经济价值（简称灌溉水经济价值）即水资源被分配到农 业生产中所创造的经济价值 ${ }^{[3]}$ 。灌溉水经济价值的核算是农业水价定价的基础 ${ }^{[4]}$ ，当水价 定价低于灌溉水经济价值时, 农户能够从使用水资源中获得超额利润, 随着水价提高, 这种超额利润被压缩，农户将有动机改变用水习惯，减少用水浪费，以获取更多超额利 润; 当水价超过灌溉水经济价值时, 农户使用水资源的成本要高于其创造的经济价值, 此时农户将有可能调整种植结构, 转向灌溉水经济价值更高的作物以继续获得超额利 润。因此，从这个角度衡量，灌溉水经济价值计算结果可作为水价定价的上限参考。

近年国际上关于灌溉水经济价值已有一些初步的研究成果，主要集中在两个方面：

收稿日期：2018-08-24；修订日期：2019-01-09

基金项目：国家水体污染控制与治理科技重大专项（2018ZX07111001）

作者简介：刘维哲（1995-), 男, 山东临沂人, 博士研究生, 研究方向为资源经济与环境管理。

E-mail: liuvzhe@126.com

通讯作者：王西琴（1965- ), 女，陕西西安人，教授，博士生导师，研究方向为资源经济与环境管理。

E-mail: wxiqin@ruc.edu.cn 
（1）从区域特征角度关注灌溉水经济价值的空间差异，从而为农业用水的有效分配 提供依据。Rigby 等 ${ }^{[5]}$ 使用选择试验法研究了西班牙不同地区灌溉水经济价值的差异，发 现缺水地区灌溉水经济价值高于丰水地区; Barton 等 ${ }^{\left[{ }^{6]}\right.}$ 、Muchara 等 ${ }^{[7]}$ 分别对印度 Tungabhadra 流域和南非Mooi 流域上下游之间灌溉水经济价值差异进行研究; Kiprop 等 ${ }^{[8]}$ 以肯尼 亚Kerio 地区为例，使用剩余价值法对不同地形条件下灌溉水经济价值进行研究，发现平 原作物灌溉水经济价值要高于盆地作物。

（2）研究不同作物类型的灌溉水经济价值，为分类作物的水价制定或者种植结构调 整提供依据。Speelman 等 ${ }^{[9]}$ 基于南非西北省地区小规模灌溉农户的调研数据，使用剩余 价值法研究发现蔬菜的灌溉水经济价值高于粮食作物; Mesajurado 等 ${ }^{[10]}$ 使用生产函数法 估计得到橄榄的灌溉水经济价值为 0.6 欧元 $/ \mathrm{m}^{3}$ ，高于同流域谷物作物；Ziolkowska ${ }^{[1]}$ 对美 国得克萨斯州 5 种粮食作物灌溉水经济价值的研究结果，成为当地稀缺水资源在作物间 有效分配的依据。目前国内对灌溉用水经济价值的研究相对较少, 张秋平等 ${ }^{[4]}$ 以黄淮海地 区粮食作物为例，使用 C-D生产函数计算得到三种粮食作物平均灌溉水经济价值为 1.02 元 $/ \mathrm{m}^{3}$ 。李良县等 ${ }^{[12]}$ 、张志霞等 ${ }^{[13]}$ 对一、二、三产业中水资源经济价值进行研究和比 较，发现水资源经济价值在第一产业中最低。

通过文献梳理发现，灌溉水经济价值的定量研究方法主要有生产函数法、选择试验 法和剩余价值法等。生产函数法需要对函数形式作出假设, 因此不可避免地受到函数设 定偏差的影响, 而受到一些学者的质疑 ${ }^{[14]}$ 。选择试验法在发展中国家的适用性也存在争 议，大多数发展中国家长期以来一直由政府以极低的价格甚至免费供应灌溉水，农户对 水资源价值的认知存在偏差，因此使用选择试验法容易低估灌溉水的经济价值。剩余价 值法既能避免生产函数法中函数设定的误差，也能克服选择试验法中农户主观认知偏差 的影响, 近年来在国际上得到了广泛的应用。此外, 剩余价值法具有较强的可操作性, 适用于水资源为关键生产要素的农业领域研究 ${ }^{[15]}$ 。本文以陕西关中地区微观农户调研数 据为依据, 采用剩余价值法对小麦、玉米和苹果三种作物灌溉水经济价值进行研究, 并 使用分位数回归模型对影响因素进行分析, 揭示研究区不同作物灌溉水经济价值的差异 及其关键的影响因素，为农业水价改革和水资源的有效分配提供参考。

\section{1 研究方法与数据来源}

\section{1 研究区概况}

关中地区地处陕西省中部，包括宝鸡峡、交口抽渭、泾惠渠、桃曲坡、石头河、洛 惠渠、石堡川、冯家山及羊毛湾九大灌区, 覆盖宝鸡、咸阳、西安、渭南和铜川 5 市, 总面积约为 2.2 万 $\mathrm{km}^{2}$ 。关中地区地处大陆性季风气候区, 具有降水分布不均的特点, 多 年平均降雨量为 $600 \mathrm{~mm}$, 属于中国典型的半干旱地区。关中地区灌溉历史悠久, 2015 年灌区有效灌溉面积 843.15 万亩，占陕西省有效灌溉面积的 $43.46 \%$ ，近年来已成为陕西 省重要的粮食及经济作物生产基地。目前关中地区水资源十分紧缺，单位土地面积水资 源占有量为全国平均水平的 $1 / 6$, 人均水资源占有量仅为全国平均水平的 $1 / 8$ 。现关中地 区九大灌区灌溉水费实行按量计收，每个农户持有一张由省物价局统一印制灌溉收费明 白卡，记录每次灌溉的水量和水费。灌区执行 2004 年陕西省物价局、省水利厅确定的水 价标准，实行终端水价制度，由工程供水费、基层管理费和群管费三部分组成，水价介 
于 $0.17 \sim 0.45$ 元 $/ \mathrm{m}^{3}$, 平均灌溉水价为 0.26 元 $/ \mathrm{m}^{3}$ 。

\section{2 数据来源}

本文数据来源于 2015 年 8 月、9月对陕西省关中地区共 7 个灌区的农户调研问卷。在 每个灌区选取两个乡镇, 每个乡镇选取两个村进行调研, 共计走访了 14 个乡镇, 28 个 村。调研对象为当地灌区种植小麦、玉米和苹果的农户，通过一对一访谈的方式共收集 问卷 236 份，其中有效问卷 215 份。

\section{3 研究方法}

\subsection{1 剩余价值法}

其核心思想是当除水以外的所有投人要素都获得同其机会成本相匹配的价格时，总 产出价值的剩余部分可以归于水资源投人要素，由此在获取农户生产的投人产出数据基 础上, 可以测算水资源的经济价值。该方法有三个重要的前提假设：一是完全理性的生 产者以追求利润最大化为目标; 二是除水以外市场是完全竞争的，故总产出的价值等于 所有投人要素的总机会成本; 三是非水要素的机会成本由其边际价值计算得到, 而边际 价值由市场价格给定 ${ }^{[7]}$ 。本文首先构建农业生产投人产出函数的一般表达式为:

$$
Y=f\left(M_{s}, M_{f}, M_{h}, M_{m}, M_{l}, M_{l d}, M_{w}\right)
$$

式中： $Y$ 为种植业总产出 $(\mathrm{kg}$ /亩 $) ; M_{s}$ 为种子投人量 $(\mathrm{kg}$ /亩 $) ; M_{f}$ 为化肥投入量 $(\mathrm{kg}$ /亩 $) ; M_{h}$ 为农药投人量 $(\mathrm{L} /$ 亩 $) ; M_{m}$ 为机械投人量 (小时/亩); $M_{l}$ 为劳动投人量 (工日/亩); $M_{l d}$ 为土地投人量 (标准化为 1 亩); $M_{w}$ 为面积灌溉水量 $\left(\mathrm{m}^{3} /\right.$ 亩)。如果假 定技术因素不变, 根据生产总值计算方法, 式 (1) 可以转换为:

$$
\left(Y \times P_{y}\right)=\left(P_{s} \times M_{s}\right)+\left(P_{f} \times M_{f}\right)+\left(P_{h} \times M_{h}\right)+\left(P_{m} \times M_{m}\right)+\left(P_{l} \times M_{l}\right)+\left(P_{l d} \times M_{l d}\right)+\left(R V_{w} \times M_{w}\right)
$$

式中: $P_{y}$ 为产出作物的市场价格; $\left(Y \times P_{y}\right)$ 表示单位面积的总产值; $i$ 代表不同要素投 人。根据假设, 投人要素 $M_{i}$ 的边际价值用市场价格 $P_{i}$ 表示, 因此 $\left(P_{i} \times M_{i}\right)$ 为要素 $M_{i}$ 的机会成本。由于水资源作为一种准公共物品, 其市场价格无法直接得到, 以 $R V_{w}$ 表示 其边际价值 $P_{w}$, 此时, 总产值 $\left(Y \times P_{y}\right)$ 扣除各项非水成本投人 $\left(\sum_{i} P_{i} M_{i}\right)$ 后得到 $\left(Y \times P_{y}-\sum_{i} P_{i} M_{i}\right)$, 可视为农业生产中单位面积的水经济价值 $\left(R V_{w} \times M_{w}\right)$ :

$$
\left.\left(R V_{w} \times M_{w}\right)=\left(Y \times P_{y}\right)-\left[P_{s} \times M_{s}\right)+\left(P_{f} \times M_{f}\right)+\left(P_{h} \times M_{h}\right)+\left(P_{m} \times M_{m}\right)+\left(P_{l} \times M_{l}\right)+\left(P_{l d} \times M_{l d}\right)\right]
$$

因此, 得到水的经济价值 $R V_{w}$ 计算公式为:

$$
R V_{w}=\frac{Y \times P_{y}-\Sigma_{i} P_{i} M_{i}}{M_{w}}
$$

\subsection{2 分位数模型}

为进一步分析灌溉水经济价值的影响因素，本文以剩余价值法的计算结果 $R V_{w}$ 值作 为因变量, 对其影响因素进行研究。当因变量为连续型变量时一般选用OLS 模型进行回 归, 然而OLS 模型假定自变量只能影响因变量条件分布的位置, 但不能影响其分布的刻 度 ${ }^{[16]}$ ，所以使用 OLS 模型只能得到各因素对灌溉水经济价值均值的影响。而分位数回归 提供了在不同被解释变量分位数下估计解释变量影响的方法, 能够更加全面地识别在不 同灌溉水经济价值水平上各影响因素的影响程度。此外, 该方法受极端值影响的概率较 
小，其回归系数也更加稳健。因此，本文选用分位数模型进行影响因素分析。

分位数模型（Quantile Regression）最早由 Koenker等 ${ }^{[17]}$ 提出，在该模型中，分位点 $\theta$ 的分位函数 Quant $_{\theta}\left(y \mid X_{i}\right)$ 可定义为:

$$
\operatorname{Quant}_{\theta}\left(y \mid X_{i}\right)=\inf \{y: F(y) \geqslant \theta, 0<\theta<1\}
$$

$F(y)$ 为因变量 $y$ 在自变量 $X_{i}$ 的概率分布函数，构建基准分位数回归模型如下:

$$
\operatorname{Quant}_{\theta}\left(y \mid X_{i}\right)=\beta_{0}^{\theta}+\beta_{i}^{\theta} X_{i}+\mu_{i}^{\theta}
$$

式中: $\operatorname{Quant}_{\theta}\left(y \mid X_{i}\right)$ 表示因变量 $y$ 在给定 $X_{i}$ 情况下与分位点 $\theta \quad(0<\theta<1)$ 对应的条件分 位函数; $\beta_{0}^{\theta}$ 和 $\mu_{i}^{\theta}$ 分别为分位点 $\theta$ 对应的常数项和随机扰动项; $X_{i}$ 为自变量 ; $\beta_{i}^{\theta}$ 被称为 “ $\theta$ 分位数回归系数”。此时分位函数可以通过最小化绝对离差加权和来求解，即：

$$
\operatorname{Quant}_{\theta}\left(y \mid X_{i}\right)=\arg \min \mathrm{E}\left[\rho_{\theta}\left(y-\beta_{0}^{\theta}-X_{i} \beta_{i}^{\theta}\right)\right]
$$

式中： $\rho_{\theta}$ 为 “校验系数”, 对正负数分别赋予权重。实际应用中，一般通过线性规划的 方法对相关参数进行估计, 式 (7) 可以转变如下:

$$
\beta_{i}^{\theta}=\operatorname{argmin}\left\{\sum_{y \geq X_{i} \beta_{i}^{\theta}} \theta\left|y-\beta_{0}^{\theta}-X_{i} \beta_{i}^{\theta}\right|+\sum_{y<X_{i} \beta_{i}^{\theta}}(1-\theta)\left|y-\beta_{0}^{\theta}-X_{i} \beta_{i}^{\theta}\right|\right\}
$$

\section{4 参数与变量}

\subsection{1 剩余价值模型参数获取}

Lange 等 ${ }^{[18]}$ 指出, 剩余价值法对变量的疏漏和非水要素的市场价格较为敏感。因此, 在应用该方法时需要收集全面且准确的农业生产投人数据。在实际调研中, 作物总产出 $\left(P_{y} Y\right)$ 、种子成本 $\left(P_{s} M_{s}\right)$ 、化肥 $\left(P_{f} M_{f}\right)$ 、农药 $\left(P_{h} M_{h}\right)$ 成本、单位面积灌溉水量 $\left(M_{w}\right)$ 通过直接询问农户获得。其中苹果树苗由于一次培育后寿命可达 50 年，为确保数 据精确性，通过询问农户苹果树育苗期内各项物料投人，将苹果种子成本投人按照一般 20 年产果期进行折现均摊。机械成本 $\left(P_{m} M_{m}\right)$ 数据分为两种情况, 一种是自有农业机 械的农户，通过询问购买费用、运营维修费用，并按照预估使用年限进行折现均推到当 年计算。另外一种是对于租用农业机械的农户，以当年实际租赁农业机械费用计算。劳 动投人 $\left(P_{l} M_{l}\right)$ 变量包括雇工费用和家庭用工折价两部分, 其中, 由于家庭劳动力不进 人劳动市场, 无法直接获得其成本, 因此, 家庭用工成本通过询问家庭劳动力在种植各 环节中投人的工日, 并乘以当地当年平均雇工价格计算得到。土地要素变量 $\left(P_{l d} M_{l d}\right)$ 参考《全国农产品成本收益资料汇编 2015》中陕西地区平均土地成本 82.93 元/亩。不同 要素成本投入的均值见表 1 。

\subsection{2 影响因素选择}

目前国外学者从不同视角对灌溉水经济价值影响因素进行了研究, Speelman 等 ${ }^{[9]}$ 发

表 1 不同作物各生产要素投入的均值统计

Table 1 Mean value statistics of different inputs of different crops

\begin{tabular}{cccccccc}
\hline 作物 & $\begin{array}{c}\text { 种子 } P_{s} M_{s} \\
\text { (元/亩) }\end{array}$ & $\begin{array}{c}\text { 化肥 } P_{f} M_{f} \\
/(\text { 元/亩 })\end{array}$ & $\begin{array}{c}\text { 农药 } P_{h} M_{h} \\
/(\text { 元/亩) }\end{array}$ & $\begin{array}{c}\text { 机械 } P_{m} M_{m} \\
\text { /(元/亩) }\end{array}$ & $\begin{array}{c}\text { 劳动 } P_{l} M_{l} \\
/(\text { 元/亩 })\end{array}$ & $\begin{array}{c}\text { 土地 } P_{l d} M_{l d} \\
/(\text { 元/亩 })\end{array}$ & $\begin{array}{c}\text { 灌溉水 } M_{w} \\
/\left(\mathrm{m}^{3} / \text { 亩 }\right)\end{array}$ \\
\hline 小麦 & 66.24 & 163.53 & 31.60 & 118.87 & 164.34 & 82.93 & 377.15 \\
玉米 & 50.82 & 167.93 & 31.62 & 117.71 & 221.27 & 82.93 & 421.23 \\
苹果 & 4.02 & 922.00 & 430.47 & 95.67 & 796.80 & 82.93 & 487.44 \\
\hline
\end{tabular}


现作物类型和灌溉方式是灌溉水经济价值的主要影响因素。Muchara等 ${ }^{[7]}$ 发现农户教育程 度、灌溉周期和地块位置对灌溉水经济价值具有显著影响。国内已有研究多是针对灌溉 用水的使用效率，分析农户个人特征、经营特征、灌溉条件等对灌溉水使用效率的影 响 ${ }^{[19-22]}$, 缺乏对灌溉水经济价值影响因素的研究。本文在参考国内外相关文献基础上, 综 合考虑农业生产的内、外部因素和主、客观条件，选取农户和家庭特征、生产经营特 征、主观认知特征以及外部政策制度特征等 4 个层面共 15 个变量进行影响因素研究。具 体变量定义见表 2 。

\section{表 2 灌溉水经济价值影响因素选取}

Table 2 Impact factors of the economic value of irrigation water

\begin{tabular}{|c|c|c|}
\hline 类别 & 变量名称 & 含义 \\
\hline \multirow[t]{5}{*}{ 农户和家庭特征 } & 年龄 & 农户的年龄 \\
\hline & 受教育水平 & $1=$ 未上学; $2=$ 小学; $3=$ 初中; $4=$ 高中或中专; $5=$ 大专及以上 \\
\hline & 主要职业 & $0=$ 务农; 1=非农职业 \\
\hline & 家庭非农劳动力人数 & 家庭人口中从事非农职业的劳动力人数 \\
\hline & 家庭经济情况在本村的水平 & $1=$ 较差; $2=$ 中等偏下; $3=$ 中等; $4=$ 中等偏上; $5=$ 较好 \\
\hline \multirow[t]{4}{*}{ 生产经营特征 } & 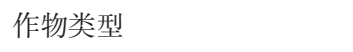 & 1=小麦；2=玉米; 3=苹果 \\
\hline & 种植面积 & 农户该种作物种植面积 \\
\hline & 耕地块数 & 该作物耕地细分块数 \\
\hline & 灌溉水紧缺程度 & $1=$ 非常充足; $2=$ 比较充足; $3=$ 一般; $4=$ 比较紧缺; $5=$ =严重紧缺 \\
\hline \multirow[t]{4}{*}{ 主观认知特征 } & 灌溉用水是否商品 & $0=$ 不是； $1=$ 是 \\
\hline & 灌溉用水是否应该付费 & $0=$ 不应该 $; 1=$ 应该 \\
\hline & 水价上涨是否愿意节水灌溉 & $0=$ 不愿意; $1=$ 愿意 \\
\hline & 若补贴是否愿意节水灌溉 & $0=$ 不愿意; $1=$ 愿意 \\
\hline \multirow[t]{2}{*}{ 外部政策制度特征 } & 是否农业水价综合改革试点 & $0=$ 否; $1=$ 是 \\
\hline & 是否加人农民用水协会 & $0=$ 否; $1=$ 是 \\
\hline
\end{tabular}

\section{2 结果分析}

\section{1 灌溉水经济价值计算结果}

表 3 为根据式 (4) 计算得到的小麦、玉米和苹果三种作物灌溉水经济价值的均值统 计，样本中小麦的灌溉水经济价值平均值为 0.66 元 $/ \mathrm{m}^{3}$ ，玉米为 0.84 元 $/ \mathrm{m}^{3}$ ，经济作物苹 果的灌溉水经济价值均值远高于粮食作物小麦和玉米，为 3.17 元 $/ \mathrm{m}^{3}$ 。

关中各灌区现行水价介于 $0.13 \sim 0.45$ 元 $/ \mathrm{m}^{3}$ 之间，本文分别以灌溉水经济价值计算结 果 0.66 元 $/ \mathrm{m}^{3} 、 0.84$ 元 $/ \mathrm{m}^{3} 、 3.17$ 元 $/ \mathrm{m}^{3}$ 作为小麦、玉米和苹果的灌溉水价上限，与现行水

\section{表 3 关中地区不同作物灌溉水经济价值计算结果均值统计}

Table 3 Mean value statistics of economic value of irrigation water

\begin{tabular}{cccccc}
\hline 作物 & $\begin{array}{c}\text { 样本量 } \\
\text { /份 }\end{array}$ & $\begin{array}{c}\text { 总产出 } Y \times P_{y} \\
\text { (元/亩) }\end{array}$ & $\begin{array}{c}\text { 非水成本 } \sum P_{i} M_{i} \\
\text { (元/亩) }\end{array}$ & $\begin{array}{c}\text { 单位土地灌溉水经济价值 } \\
Y \times P_{y}-\sum P_{i} M_{i} /(\text { 元/亩) }\end{array}$ & $\begin{array}{c}\text { 灌溉水经济价值 } \\
R V_{w} /\left(\text { 元 } / \mathrm{m}^{3}\right)\end{array}$ \\
\hline 小麦 & 78 & 875.96 & 627.52 & 248.44 & 0.66 \\
玉米 & 74 & 1025.37 & 672.27 & 353.10 & 0.84 \\
苹果 & 63 & 3878.63 & 2331.87 & 1546.76 & 3.17 \\
\hline
\end{tabular}


价进行比较可以发现，前三种作物的水价均有上调空间，粮食作物水价调整空间较小， 介于 $0.24 \sim 0.71$ 元 $/ \mathrm{m}^{3}$ ，苹果的水价调整空间则更为宽松，介于 $2.72 \sim 3.04$ 元 $/ \mathrm{m}^{3}$ 之间。本文 计算结果与已有研究结果相比具有一致性：李鹏 ${ }^{[23]}$ 使用补偿费用水价模型，从水资源消 耗成本、直接生产成本、外部成本三个方面对关中地区灌溉用水的可持续利用价格进行 测算, 结果为 0.43 元 $/ \mathrm{m}^{3}$; 任梅芳 ${ }^{[24]}$ 使用模糊数学综合评价模型对关中地区灌溉水价格进 行估计, 为 0.27 元 $/ \mathrm{m}^{3}$; 徐飘 ${ }^{[25]}$ 采用成本收益法计算的水价为 0.51 元 $/ \mathrm{m}^{3}$, 农户承受能力的 水价为 0.62 元 $/ \mathrm{m}^{3}$ 。以上结果均反映了当前关中地区水价具有上调空间, 但并未对粮食和 经济作物进行分类讨论。

\section{2 影响因素分析}

根据分位数回归模型及选取指标，按照灌溉水经济价值从低到高顺序依次选择 $0.25 、 0.5 、 0.75 、 0.9$ 四个具有代表性的分位点进行回归分析。同时，为了保证结果的稳 健型, 采用自助法 (Bootstrap) 进行不断有放回的抽样, 根据得到的自助样本对总体进 行统计推断，以获得更加渐进有效的估计量，回归结果列人表 4 。

\section{(1) 农户和家庭特征}

在灌溉水经济价值较低时 $(q=0.25)$ 时，所有农户和家庭特征均呈现显著相关性。 其中, 年龄、以非农为主要职业和家庭非农劳动力人数为负向影响, 说明年龄越大、分 配在务农中精力越少的农户其农业生产中水资源的经济价值越低; 受教育程度和家庭经

表 4 灌溉水经济价值影响因素分位数回归结果

Table 4 Results of quantile regression analysis

\begin{tabular}{|c|c|c|c|c|c|c|c|c|c|}
\hline \multirow{2}{*}{ 类别 } & \multirow{2}{*}{ 变量 } & \multicolumn{8}{|c|}{ 分位数回归结果 } \\
\hline & & \multicolumn{2}{|c|}{$q=0.25$} & \multicolumn{2}{|c|}{$q=0.5$} & \multicolumn{2}{|c|}{$q=0.75$} & \multicolumn{2}{|c|}{$q=0.9$} \\
\hline \multirow{5}{*}{$\begin{array}{l}\text { 农户和 } \\
\text { 家庭特征 }\end{array}$} & 年龄 & $-0.01^{* *}$ & $(0.01)$ & -0.00 & $(0.01)$ & 0.02 & $(0.01)$ & 0 & $(0.02)$ \\
\hline & 教育水平 & $0.23^{* * * *}$ & $(0.08)$ & 0.16 & $(0.12)$ & 0.03 & $(0.18)$ & 0.04 & $(0.24)$ \\
\hline & 主要职业 & $-0.56^{*}$ & $(0.29)$ & -0.32 & $(0.42)$ & -0.53 & $(0.38)$ & -0.79 & $(0.49)$ \\
\hline & 家庭非农劳动力人数 & $-0.10^{* *}$ & $(0.05)$ & -0.07 & $(0.07)$ & -0.04 & $(0.08)$ & -0.10 & $(0.13)$ \\
\hline & 家庭经济水平 & $0.20^{* * *}$ & $(0.07)$ & $0.31^{* * *}$ & $(0.07)$ & $0.47^{* * *}$ & $(0.15)$ & 0.38 & $(0.23)$ \\
\hline \multirow{6}{*}{$\begin{array}{l}\text { 生产经营 } \\
\text { 特征 }\end{array}$} & 作物类型a & & & & & & & & \\
\hline & 玉米 & 0.05 & $(0.11)$ & 0.12 & $(0.11)$ & 0.12 & $(0.15)$ & 0.07 & $(0.24)$ \\
\hline & 苹果 & $0.62^{*}$ & $(0.33)$ & $1.97^{* * *}$ & $(0.56)$ & $4.00^{* * *}$ & $(0.82)$ & $6.82^{* * *}$ & $(2.02)$ \\
\hline & 种植面积 & 0 & $(0.02)$ & 0 & $(0.02)$ & -0.01 & $(0.03)$ & -0.02 & $(0.06)$ \\
\hline & 耕地块数 & $-0.15^{* *}$ & $(0.08)$ & $-0.20^{* *}$ & $(0.09)$ & -0.24 & $(0.15)$ & -0.15 & $(0.23)$ \\
\hline & 灌溉水紧缺程度 & 0.06 & $(0.05)$ & 0.05 & $(0.06)$ & 0 & $(0.08)$ & -0.15 & $(0.16)$ \\
\hline \multirow{4}{*}{$\begin{array}{l}\text { 主观认知 } \\
\text { 特征 }\end{array}$} & 灌溉用水是商品 & -0.09 & $(0.17)$ & 0.13 & $(0.24)$ & $0.51^{*}$ & $(0.31)$ & 0.38 & $(0.38)$ \\
\hline & 灌溉用水应该付费 & 0.49 & $(0.17)$ & 0.39 & $(0.27)$ & 0.35 & $(0.32)$ & -0.44 & $(0.98)$ \\
\hline & 水价上涨愿节水灌溉 & -0.17 & $(0.15)$ & 0.05 & $(0.18)$ & -0.04 & $(0.38)$ & $1.33^{* *}$ & $(0.64)$ \\
\hline & 若补贴愿节水灌溉 & 0.10 & $(0.19)$ & 0.03 & $(0.24)$ & 0.42 & $(0.37)$ & $1.26^{*}$ & $(0.64)$ \\
\hline \multirow{4}{*}{$\begin{array}{l}\text { 外部政策 } \\
\text { 制度特征 }\end{array}$} & 已进行水价改革试点 & $0.53^{* * *}$ & $(0.13)$ & $0.61^{* * *}$ & $(0.15)$ & $0.64^{* * *}$ & $(0.23)$ & $0.96^{* * *}$ & $(0.37)$ \\
\hline & 加人农民用水协会 & -0.19 & $(0.12)$ & 0 & $(0.13)$ & 0.32 & $(0.24)$ & $0.72^{*}$ & $(0.42)$ \\
\hline & 常数 & -0.26 & $(0.55)$ & -0.62 & $(0.80)$ & -0.80 & $(1.27)$ & 0.90 & $(2.12)$ \\
\hline & $R^{2}$ & 0.08 & & 0.11 & & 0.24 & & 0.38 & \\
\hline
\end{tabular}

注：1. 参照组 $\mathrm{a}=$ 小麦; $2 .{ }^{*}$ 、“*和***分别在 $10 \% 、 5 \% 、 1 \%$ 的水平上显著。 
济水平均在 $1 \%$ 统计水平上显著且影响方向为正, 这与许朗等 ${ }^{[26]}$ 的研究结论一致, 受教育 程度较高往往代表农户掌握更好的灌溉技术，而良好的家庭经济水平则意味着农户有更 充沛的资金对灌溉设施进行更新和维护，这都有助于提高水资源使用效率，获得更高的 经济价值。

随着分位点的提高, 农户和家庭特征层面的影响因素逐渐减少。在分位点 0.5 和 0.75 处, 仅有家庭经济水平仍然有正向影响，而在 0.9 分位点处，家庭经济水平也不再显著。 说明农户个人特征仅在灌溉水经济价值较低时产生影响, 家庭经济水平影响的变化趋势 可能意味着当灌溉水经济价值较高时 $(q=0.9)$, 灌溉水的使用已经具有很高的经济效 率, 增加灌溉设施投人对提升灌溉水经济价值的边际作用较低, 因此农户往往不会选择 进一步增加投人，此时家庭经济水平不再具有相关性。

(2) 生产经营特征

作物类型是本文关注的重点，不同作物类型的选择代表水资源被分配到不同用途。 从回归结果看, 作物类型由小麦变为玉米在所有分位点上均无显著影响, 而由小麦变为 苹果则在所有分位点处显著正相关。说明当小麦种植中的水资源被分配给同为粮食作物 的玉米时, 灌溉水经济价值不发生明显变化, 而被分配到经济作物苹果种植中则会带来 灌溉水经济价值的明显提升。意味着种植作物类型的转变跨粮经作物时, 作物类型是影 响灌溉水经济价值的重要因素。这与 Speelman 等 ${ }^{[0]}$ 的研究结果一致, 作物类型是主要影 响因素, Hussain 等 ${ }^{[27]}$ 基于非洲农业的研究也得到相似结果。随着分位点的提高, 转为种 植苹果对灌溉水经济价值的正向影响程度也随之增加。进一步揭示当灌溉水经济价值处 于较高水平时由种植小麦转为种植苹果, 能够更大程度地提升灌溉水经济价值。

耕地块数在 0.25 和 0.5 分位点上显著且影响方向为负, 说明耕地细碎化会降低灌溉水 经济价值, 但是在 0.75 和 0.9 分位点上不再具有显著相关性。种植面积和灌溉用水紧缺程 度在所有分位点上不显著, 这可能同研究区域特点有关, 关中地区种植以小规模为主, 规模效应难以体现，而小麦、玉米和苹果是当地主要种植作物，即使在水资源紧缺情况 下农户也往往优先配置足够的灌溉水量。

(3) 主观认知特征

农户主观认知特征衡量农户对水资源价值的认知程度和对节水灌溉的接受意愿，一 般来说，农户对水资源价值越认同、对节水灌溉越容易接受，其在种植中会有更强的节 水意识, 避免灌溉过程中不必要的水资源浪费行为, 提高灌溉用水效率。但是在分位回 归结果中, 在 0.25 和 0.5 分位点上所有主观认知特征并无显著影响, 在 0.75 和 0.9 高分位 点水平上农户主观认知特征开始显著且其影响方向为正。说明对于灌溉水经济价值低下 的农户，受限于生产技术和设施条件水平的影响，这种主观认知难以转化为有效的用水 效率提高行为，而高用水经济价值农户则更容易将主观认知进行实践转化。

（4）外部政策制度特征

农业水价综合改革是包含加强灌排设施管理、建立精准用水补贴和节水奖励等举措 在内的一系列机制创新, 本文调研的 7 个灌区中有两个属于水价综合改革的试点灌区。 是否进行农业水价综合改革试点, 变量在所有分位点上通过了 $1 \%$ 统计水平的显著性检验 且其影响方向为正, 说明水价综合改革试点在各分位点上对农户的激励作用都是有效 的。此外, 其系数随分位点提高而递增, 意味着随着水经济价值的提高, 农户能更好地 适应和利用水价改革政策，外部政策作用的边际效果在逐渐增加。农户是否加人用水者 
协会在大部分分位点上并不显著，仅在最高分位点 0.9 有正向影响。

\section{3 结论与讨论}

本文使用剩余价值法对陕西关中地区小麦、玉米和苹果三种主要作物灌溉水经济价 值进行了计算, 并分析其影响因素, 得出以下主要结论：

（1）关中地区小麦和玉米作物的灌溉水经济价值比较低，分别为 0.66 元 $/ \mathrm{m}^{3}$ 、 0.84 元 $/ \mathrm{m}^{3}$, 经济作物苹果为 3.17 元 $/ \mathrm{m}^{3}$ 。灌溉水经济价值在粮食作物和经济作物中的显著 差异说明单一的农业水价定价并不合理，难以体现不同作物种植中的用水效益。目前关 中地区只有石堡川灌区进行了农业用水分类定价，应当继续推进农业水价分类定价，对 粮食作物和经济作物实行差别定价。

（2）小麦和玉米的水价提升空间介于 $0.24 \sim 0.71$ 元 $/ \mathrm{m}^{3}$, 苹果的水价提升空间较为宽 松，介于 $2.72 ~ 3.04$ 元 $/ \mathrm{m}^{3}$ 之间。这意味着对粮食作物来说，单纯以提高水价的方式达到 农业节水目的并不合适。粮食作物的水价调整空间较小，若上调现行灌溉水价将进一步 压缩粮食种植利润，从而可能引起当地种植结构的变化。而经济作物的水价调整空间则 较为宽松，可以灵活运用水价定价政策以促进关中地区水资源合理利用。值得注意的 是，由于剩余价值法需基于一定的前提假设，因此本文计算结果不能完全反映水资源的 实际价值，仅作为水价调整上限的参考。在实际水价调整中应当谨慎、综合考虑多方面 因素，如农民承受能力等问题。

（3）粮食作物之间的转换并不会显著影响灌溉水经济价值，而当由粮食作物转为经 济作物时, 作物类型是影响灌溉水经济价值的最主要因素。识别不同作物类型对灌溉水 经济价值影响的差异有利于促进水资源在农业中更有效的分配，鼓励水资源被更多地分 配到经济作物中能够提高关中地区水资源所创造的经济价值，但是需要同时考虑关中地 区的粮食安全保障功能。

（4）农户和家庭特征以及土地分散程度在灌溉水经济价值较低时为主要影响因素, 而在较高的分位点上不再显著; 农户主观认知和加人农民用水者协会仅在灌溉水经济价 值较高时显著正相关。这意味着在灌溉水经济价值较低时，通过宣传等手段提升农户对 节水灌溉的主观认知并不能带来灌溉水经济价值的提升，因为农户迫于灌溉技术和灌溉 设施等条件限制，难以将主观认知进行有效的实践转化，所以政府对农户进行灌溉技术 培训、改善土地细碎状况以及加大灌溉设施建设将能更为有效地提高灌溉水经济价值; 在灌溉用水经济价值较高时，应当大力增强农户的灌溉节水意识，通过用水者协会将他 们组织起来可能也是提高灌溉水经济价值的有效手段。此外，在本文中农业水价综合改 革试点作为一种外部政策变量对灌溉水经济价值呈现正向影响, 但是受篇幅所限并未进 行深人研究，该政策对灌溉水经济价值的影响仍有待进一步全面评估。

\section{参考文献(References):}

[1] 康绍忠. 水安全与粮食安全. 中国生态农业学报, 2014, 22(8): 880-885. [KANG S Z. Towards water and food security in China. Chinese Journal of Eco-Agriculture, 2014, 22(8): 880-885.]

[2] WARD F A, MICHELSEN A. The economic value of water in agriculture: Concepts and policy applications. Water Policy, 2002, 4(5): 423-446.

[3] YOUNG R A, LOOMIS J B. Determining the Economic Value of Water: Concepts and Methods. London: Routledge Press, 2005.

[4] 张秋平, 郝晋珢, 白玮. 黄淮海地区粮食生产中的农业水资源经济价值核算. 农业工程学报, 2008, 24(2): 1-5. 
[ZHANG Q P, HAO J M, BAI W. Estimation of economic value of agricultural water resource in grain production in Huang-Huai-Hai region. Transactions of the CSAE, 2008, 24(2): 1-5.]

[5] RIGBY D, ALCON F, BURTON M. Supply uncertainty and the economic value of irrigation water. European Review of Agricultural Economics, 2010, 37(1): 97-117.

[6] BARTON D N, TARON A, STALNACKE P, et al. Valuing irrigation water using survey-based methods in the Tungabhadra River Basin, India. Irrigation \& Drainage Systems, 2010, 24(3-4): 265-277.

[7] MUCHARA B, ORTMANN G, MUDHARA M, et al. Irrigation water value for potato farmers in the Mooi River irrigation scheme of KwaZulu-Natal, South Africa: A residual value approach. Agricultural Water Management, 2016, 164(2): 243-252.

[8] KIPROP J K, LAGAT J K, MSHENGA P, et al. Determining the economic value of irrigation water in Kerio Valley Ba$\sin$ (Kenya) by residual value method. Journal of Economics and Sustainable Development, 2015, 6(7): 102-107.

[9] SPEELMAN S, FAROLFI S, PERRET S, et al. Irrigation water value at small-scale schemes: Evidence from the north west province, South Africa. International Journal of Water Resources Development, 2008, 24(4): 621-633.

[10] MESAJURADO M A, BERBEL J, ORGAZ F. Estimating marginal value of water for irrigated olive grove with the production function method. Spanish Journal of Agricultural Research, 2010, 8(S2): 197-206.

[11] ZIOLKOWSKA J R. Shadow price of water for irrigation: A case of the High Plains. Agricultural Water Management, 2015, 153: 20-31.

[12] 李良县, 甘泓, 汪林, 等. 水资源经济价值计算与分析. 自然资源学报, 2008, 23(3): 494-499. [LI L X, GAN H, WANG L, et al. Calculation and analysis of the economic value of water resource. Journal of Natural Resources, 2008, 23(3): 494-499.]

[13] 张志霞, 秦昌波, 贾仰文, 等. 缺水地区水资源经济价值的异同辨析: 以北京市和陕西省为例. 中国人口·资源与环 境, 2012, 22(10): 19-25. [ZHANG Z X, QIN C B, JIA Y W, et al. Comparative analysis of the economic value of water in water deficient areas with different development levels: Case study of Beijing and Shaanxi, China. China Population, Resources \& Environment, 2012, 22(10): 19-25.]

[14] JIA S, LONG Q, WANG R Y, et al. On the inapplicability of the Cobb-Douglas Production Function for estimating the benefit of water use and the value of water resources. Water Resources Management, 2016, 30(10): 3645-3650.

[15] BERBEL J, MESA-JURADO M A, PISTON J M. Value of irrigation water in Guadalquivir Basin (Spain) by residual value method. Water Resources Management, 2011, 25(6): 1565-1579.

[16] 刘生龙. 教育和经验对中国居民收人的影响: 基于分位数回归和审查分位数回归的实证研究. 数量经济技术经济 研究, 2008, 25(4): 75-85. [LIU S L. Influences of education and experience on Chinese residents. Journal of Quantitative \& Technical Economics, 2008, 25(4): 75-85.]

[17] KOENKER R, BASSETT G. Regression quantiles. Econometrica, 1978, 46(1): 33-50.

[18] LANGE G M, HASSAN R. The Economics of Water Management in Southern Africa: An Environmental Accounting Approach. Cheltenham UK: Edward Elgar Publishing, 2006.

[19] 王晓娟, 李周. 灌溉用水效率及影响因素分析. 中国农村经济, 2005, (7): 11-18. [WANG X J, LI Z. Analysis of efficiency of irrigation water use and influencing factors. Chinese Rural Economy, 2005, (7): 11-18.]

[20] 王学渊, 赵连阁. 中国农业用水效率及影响因素: 基于 1997-2006年省区面板数据的 SFA 分析. 农业经济问题, 2008, 29(3): 10-18. [WANG X Y, ZHAO L G. Agricultural water efficiency and the causal factors: A stochastic frontier analysis based on Chinese provincial panel data: 1997-2006. Issues in Agricultural Economy, 2008, 29(3): 10-18.]

[21] 耿献辉, 张晓恒, 宋玉兰. 农业灌溉用水效率及其影响因素实证分析: 基于随机前沿生产函数和新疆棉农调研数 据. 自然资源学报, 2014, 29(6): 934-943. [GENG X H, ZHANG X H, SONG Y L. Measurement of irrigation water efficiency and analysis of influential factors: An empirical study based on stochastic production frontier and cotton farmers' data in Xinjiang. Journal of Natural Resources, 2014, 29(6): 934-943.]

[22] 夏莲, 石晓平, 冯淑怡, 等. 农业产业化背景下农户水资源利用效率影响因素分析: 基于甘肃省民乐县的实证分析. 中国人口·资源与环境, 2013, 23(12): 111-118. [XIA L, SHI X P, FENG S Y, et al. The impact of agriculture-related enterprises involvement in farmers investment of small-scaled irrigation and water conservancy facilities: A case study of Minle county of Gansu province. China Population, Resources \& Environment, 2013, 23(12): 111-118.]

[23] 李鹏. 可持续发展的农业水价理论与改革. 杨凌: 西北农林科技大学, 2008. [LI P. Theory and reformation of sustainable development agricultural water price. Yangling: Northwest A\&F University, 2008.]

[24] 任梅芳. 基于节水技术推广的农业节水水价研究. 杨凌: 西北农林科技大学, 2012. [REN M F. Agricultural water price based on promoting water-saving technology utilization. Yangling: Northwest A\&F University, 2012.] 
[25] 徐飘. 农业灌溉水价确定及其对农户用水行为的影响分析. 杨凌: 西北农林科技大学, 2014. [XU P. Agricultural irrigation water price determined and its impact on farmers' behavior. Yangling: Northwest A\&F University, 2014.]

[26] 许朗, 黄莺. 农业灌溉用水效率及其影响因素分析: 基于安徽省蒙城县的实地调查. 资源科学, 2012, 34(1): 105113. [XU L, HUANG Y. Measurement of irrigation water efficiency and analysis of influential factors: An empirical study of Mengcheng county in Anhui province. Resources Science, 2012, 34(1): 105-113.]

[27] HUSSAIN I, TURRAL H, MOLDEN D, et al. Measuring and enhancing the value of agricultural water in irrigated river basins. Irrigation Science, 2007, 25(3): 263-282.

\title{
Estimating economic value of irrigation water and analysis of influencing factors: \\ A case study based on residual value method and farmers' data in Guanzhong area of Shaanxi
}

\author{
LIU Wei-zhe, TANG Li, WANG Xi-qin, WANG Jian-hao \\ (School of Agricultural Economics and Rural Development, Renmin University of China, \\ Beijing 100872, China)
}

\begin{abstract}
The economic value of irrigation water is an important basis for the pricing of irrigation water. Based on farmers' data in Shaanxi Guanzhong irrigation area, this paper applied Residual Value Method to calculate the economic value of irrigation water for wheat, corn and apple. The results show that the economic values of irrigation water for the three crops are 0.66 yuan $/ \mathrm{m}^{3}, 0.84$ yuan $/ \mathrm{m}^{3}$ and $3.17 \mathrm{yuan} / \mathrm{m}^{3}$, respectively. Taking the results as the upper limit of irrigation water price and compared with the current irrigation water price, we found that the water price increase range of wheat and corn is between $0.24-0.71 \mathrm{yuan} / \mathrm{m}^{3}$. The apple water price adjustment space is relatively relaxed, ranging from 2.72 to $3.04 \mathrm{yuan} / \mathrm{m}^{3}$. Furthermore, the analysis of factors influencing economic value of water based on quantile regression shows that the main factors are family economic level, type of crops, and whether to carry out comprehensive reform of agricultural water price project. The educational level, family economic level, farmers' subjective cognitive characteristics, and whether to carry out the comprehensive reform of agricultural water price project are positively correlated with the economic value of water, while age, non-agricultural occupations, number of non-farm labor forces in family, land quantity and water economic value are negatively correlated with it. Specifically, (1) when economic value of irrigation water is at low stage, the characteristics of farmers and families as well as the farmland dispersion have significant impact; (2) when the economic value of irrigation water is at high stage, raising farmers' water-saving consciousness and joining water users association will be able to effectively improve the economic value of irrigation water; (3) the conversion from grain into cash crops and the comprehensive reform of agricultural water prices have significant positive effects on all quantile points. This paper provides the basis for the agricultural water pricing classification in Guanzhong irrigation area, and also shows a new perspective for calculating the economic value of irrigation water.
\end{abstract}

Keywords: economic value of irrigation water; influencing factors; residual value method; quantile regression; Guanzhong area 